\title{
Feasibility and Utility of Different Approaches to Violence Risk Assessment for Young Adults Receiving Treatment for Early Psychosis
}

\author{
Stephanie A. Rolin ${ }^{1,2}$ (Dennifer Scodes ${ }^{2} \cdot$ Renald Dambreville $^{2} \cdot$ Ilana R. Nossel $^{1,2} \cdot$ Iruma Bello $^{1,2}$. \\ Melanie M. Wall ${ }^{1,2} \cdot$ T. Scott Stroup ${ }^{1,2} \cdot$ Lisa B. Dixon $^{1,2} \cdot$ Paul S. Appelbaum $^{1,2}$
}

Received: 29 September 2021 / Accepted: 17 November 2021 / Published online: 4 January 2022

(c) The Author(s), under exclusive licence to Springer Science+Business Media, LLC, part of Springer Nature 2021

\begin{abstract}
This pilot study examined violence risk assessment among a sample of young adults receiving treatment for early psychosis. In this study, thirty participants were assessed for violence risk at baseline. Participants completed follow-up assessments at 3, 6, 9 and 12 months to ascertain prevalence of violent behavior. Individuals were on average 24.1 years old ( $\mathrm{SD}=3.3$ years) and predominantly male $(n=24,80 \%)$. In this sample, six people $(20 \%)$ reported engaging in violence during the study period. Individuals who engaged in violence had higher levels of negative urgency $(\mathrm{t}(28)=2.21, \mathrm{p}=0.035)$ This study sought to establish the feasibility, acceptability, and clinical utility of violence risk assessment for clients in treatment for early psychosis. Overall, this study found that most individuals with early psychosis in this study (who are in treatment) were not at risk of violence. Findings suggest that violent behavior among young adults with early psychosis is associated with increased negative urgency.
\end{abstract}

Keywords Early intervention $\cdot$ First-episode psychosis $\cdot$ Violence risk assessment $\cdot$ Violence $\cdot$ Schizophrenia

\section{Introduction}

Studies of individuals presenting for treatment of firstepisode psychosis suggest that up to one-third of patients present with a history of aggressive or violent behavior (Large \& Nielssen, 2011; Nielssen et al., 2012; Rolin et al., 2018; Winsper et al., 2013). Rates of serious violence among individuals with a first episode of psychosis are also high, estimated to be around 15\% (Large \& Nielssen, 2011). Violence in this population may precede diagnosis of psychosis, as one recent study found that nearly $40 \%$ of young adults at ultra-high risk of developing psychosis had a history of violence (Hutton et al., 2012). Past research has identified risk factors for violence among people with early psychosis, including hostile affect, criminal justice involvement, less education, being in treatment involuntarily, or substance use

Stephanie A. Rolin

Stephanie.Rolin@nyspi.columbia.edu

1 Department of Psychiatry, Columbia University Irving Medical Center, 1051 Riverside Drive, Suite 1300, New York, NY 10032, USA

2 New York State Psychiatric Institute, 1051 Riverside Drive, New York, NY 10032, USA
(Chang et al., 2015; Large \& Nielssen, 2011; Rolin et al., 2018). Among substances, cannabis appears to be most closely associated with increased rates of violence, possibly through heightened paranoia or other positive symptoms (Harris et al., 2010; Maremmani et al., 2004; Moulin et al., Moulin, Baumann, et al., 2018; Rolin et al., 2018).

Although current treatment standards endorse completion of violence risk assessments for all individuals with schizophrenia (Lehman et al., 2004), few studies describe the use of standardized tools to assess violence risk in the young population experiencing recent onset of psychosis (Purcell et al., 2012; Rolin et al., 2021). Different models of risk assessment exist, including unstructured clinical judgment, actuarial tools, and structured clinical judgment. Unstructured clinical judgment relies on a clinician to assess violence risk, based on a patient's clinical presentation, including history, available collateral information, and current mental status. While commonly used, research has shown that unstructured clinical judgment has low interrater reliability and poor predictive accuracy (Monahan, 1984; Webster et al., 1997). In contrast, actuarial tools and structured clinical judgment tools have higher predictive validity and are the preferred approach (Fazel et al., 2012; Singh et al., 2011). Actuarial tools are scored using a fixed method, 
where decisions on degree of violence risk are made based on predetermined rules. However, since actuarial tools do not allow for clinical interpretation of scores, some clinicians prefer the structured professional judgment approach, which allows evaluators to incorporate their own clinical judgment into the risk assessment. The HCR-20 is one of the most used structured professional judgment tools used to assess violence risk, and research studies have validated its use with forensic populations, sex offenders, inpatient hospitals, and community settings (Cartwright et al., 2018; Coupland \& Olver, 2018; Douglas et al., 1999; Nicholls et al., 2004; Sada et al., 2016).

In addition to these formal violence risk assessment tools, new research has also shown the value of other approaches. One incorporates a collaborative approach in working with patients on assessing their own violence risk, which research has shown is feasible especially when done in a shared-decision manner alongside assessments by staff (Papapietro, 2019; Ray \& Simpson, 2019). A study of psychiatric inpatients with co-occurring mental health and substance use disorders found that individuals were able to assess their own risk of future violence with a predictive accuracy comparable to structured violence risk assessment tools (Peterson et al., 2011; Skeem et al., 2013). However, self-assessment of violence risk has never been evaluated for a population of young adults with early psychosis, who may have more symptoms of disorganization and less insight into the determinants of their behavior since they are earlier in their course of illness (Pelizza et al., 2021; RaucherChéné et al., 2021). Another promising, novel approach is to ask individuals about violence indirectly through structured questions regarding psychotic symptoms, i.e., the P.1 Unusual Thought Content/Delusions item of the Structured Interview for Prodromal Symptoms (SIPS), which has produced new insights into violence risk (Brucato et al., $2018,2019)$. The SIPS is a semi-structured interview used to diagnose and monitor prodromal symptoms of psychosis (McGlashan et al., 2010). One study found that the P.1 item of the SIPS indirectly revealed violent ideation when individuals were discussing their unusual thought content and delusions, though the same individuals denied violent ideation when asked directly (Brucato et al., 2018). In addition, emerging research suggests that impulsivity or urgency has been identified as a target mechanism for violence in early psychosis (Hoptman, 2015; Matthew J. Hoptman et al., 2014; Moulin, Baumann, et al., 2018; Moulin, Golay, et al., 2018), suggesting that its assessment may be helpful as well.

Yet, clinical adoption of formal approaches to assess violence risk has been slow, including among early intervention services (EIS), specialized clinics providing coordinated specialty care for young adults with early psychosis. A review of the literature identified two published studies describing the use of formal risk assessment tools in EIS clinics. One study described a forensic clinic embedded within an EIS clinic (Purcell et al., 2012), to which only patients thought to be at higher risk of violence were referred for formal risk assessment and management. Of the patients referred and assessed for violence risk using the HCR-20, $13 \%$ were rated at low risk of violence, $29 \%$ at medium risk, and $42 \%$ at high risk (Purcell et al., 2012). Given that the HCR-20 was only utilized to assess violence risk for patients who were thought to be at elevated risk, its implications for the general population of patients receiving care at EIS clinics is unclear. Another study administered the HCR-20 to all young adults with early psychosis receiving care at one EIS clinic. More than two-thirds of patients were rated at low risk of future violence, with $24.5 \%$ rated as medium risk, and $7.5 \%$ as high risk (Rolin et al., 2021). However, neither of these studies sought to assess the accuracy of the HCR-20 in predicting future violent behavior in the EIS setting. In addition, no identified studies examined the use of other types of violence risk assessment in this setting (such as the COVR or self-assessment). Evaluation of the utility of other risk assessment tools is needed because they were developed and studied among general populations of people with SMI, and research has suggested that they may perform more poorly in predicting violence risk for people with schizophrenia than for other diagnoses (such as personality disorders) (Fazel et al., 2012; Grann et al., 2000; Singh et al., 2011).

Given the recent expansion of EIS programs that deliver treatment to young adults within five years of onset of nonaffective psychosis (Azrin et al., 2016; Heinssen et al., 2014), research is needed now on the performance of violence risk assessment in this population to begin moving beyond identifying risk factors to intervening to mitigate violence risk. This pilot study sought to address this gap in the literature by examining the feasibility and utility of multiple approaches to violence risk assessment among a population of young adults receiving treatment for early psychosis. First, the study tested implementation of different approaches to assessing violence risk at baseline. Then, following assessment of violence risk, participants were followed longitudinally for one year using the MacArthur Community Violence Interview, a validated, semi-structured interview that assesses whether an individual has engaged in violent behavior - the outcome measure (Appelbaum et al., 2000; Coid et al., 2016; Steadman et al., 1998; Swanson et al., 2006).

\section{Methods}

\section{Setting}

This study took place at two EIS clinics in New York State that are part of the OnTrackNY network. OnTrackNY is an 
evidence-based model of early intervention care that was developed from the National Institute of Mental Healthfunded Recovery after an Initial Schizophrenia Episode (RAISE) Connection project (Bello et al., 2017; Dixon et al., 2015). OnTrackNY provides coordinated specialty care to young adults ages 16-30 within two years of the onset of a non-affective psychosis (Heinssen et al., 2014). OnTrackNY has 23 clinic locations in New York State, including in New York City (all five boroughs), Long Island, and upstate New York. One of the clinic locations for this study was in New York City and the other in upstate New York.

\section{Study Design}

This was a longitudinal observational pilot study. All participants were assessed for violence risk at baseline, following which they completed up to four follow-up assessments of violent behavior that occurred since the last follow-up. Follow-up assessments occurred at 3, 6, 9 and 12 months. All assessments were completed by a trained assessor (SR), a forensic psychiatrist who has advanced clinical training in both EIS care and forensic assessment. Demographic information and relevant medical history (i.e., diagnoses, length of treatment) was obtained by chart review, from standardized forms collected as part of routine care at OnTrackNY. In certain cases, research staff spoke to the primary clinician when more information was needed.

\section{Participants}

Participants were receiving EIS care at a participating OnTrackNY clinic and had to remain enrolled in EIS care to continue participating in the study. Individuals are eligible for services at OnTrackNY if they: (a) are between 16 and 30 years old; (b) have a clinical diagnosis of schizophrenia, schizoaffective disorder, schizophreniform disorder, other unspecified or specified schizophrenia spectrum disorder, or delusional disorder; (c) have a history of psychotic symptoms lasting at least one week; (d) with first onset of psychotic symptoms less than two years ago; and (e) reside in New York State. Exclusion criteria for OnTrackNY include: (a) a clinical diagnosis of an intellectual disability; (b) a primary diagnosis of substance-induced psychotic disorder, mood disorder with psychotic features, or psychotic disorder due to a general medical condition; (c) a clinical diagnosis of a serious or chronic medical condition impairing functioning independent of psychosis. Individuals are eligible for care regardless of insurance status or ability to pay.

Participants were recruited from the two clinics starting in November 2019 at site \#1 and December 2019 at site \#2. One of the two participating EIS clinics has an integrated aftercare program for individuals up to five years after the onset of first psychotic symptoms. At that clinic site, individuals who had onset of first psychotic symptoms less than five years ago were included in this study; at the second site, all participants were within two years of onset. All individuals receiving EIS care at the participating locations were eligible to participate, regardless of length of treatment or prior history of violence. Clinicians referred interested individuals who were clinically stable (i.e., not judged at imminent risk of violence or self-harm requiring hospitalization) to the study. Each interested participant provided informed consent and could withdraw from the study at any time. After consent, participants completed a baseline interview.

All recruitment and follow-up assessments were intended to occur in-person. The target recruitment was 60 participants and the plan was to expand to two additional clinics in early 2020. However, in March 2020, recruitment was halted due to the COVID-19 pandemic and all subsequent follow-up assessments were transitioned to a virtual format. The final sample size included thirty participants recruited between November 2019 and February 2020 from two clinic locations.

\section{Measures}

Measures of violence risk at baseline included the following assessments: (1) HCR-20 (Arai et al., 2016; Douglas et al., 1999; Nicholls et al., 2004; Sada et al., 2016); (2) COVR (Monahan et al., 2006); (3) self-assessment (Peterson et al., 2011; Skeem et al., 2013); (4) short-UPPS-P (Cyders \& Smith, 2008; Cyders et al., 2014; Whiteside \& Lynam, 2001); and (5) the P.1 item of the SIPS (McGlashan et al., 2010). The HCR-20 is a structured risk assessment tool that assesses a person's risk of future violence as low, medium, or high (operationalized as low $=$ no risk and medium or high = any risk). The first item (item H1) of the HCR-20 was additionally isolated to assess a person's history of violence (operationalized as a score of $1=$ no history and a score of 2 or 3 = history of violence). The COVR is an actuarial risk assessment tool that produces an estimated risk of a person's violence, ranging from 1 to $76 \%$. Scores are divided into five risk categories: very low (approximately $1 \%$ risk), low (approximately 8\% risk), average (approximately $26 \%$ risk), high (approximately $56 \%$ risk), and very high (approximately $76 \%$ risk). The COVR was operationalized as very low and low =low risk, and everything else (i.e., average, high and very high risk)=elevated risk. Self-assessment took place with a Likert Scale on which participants rated their risk of future violence, from 0 (no risk) to 5 (highest risk) (operationalized as $0=$ no risk and scores above 0 as any risk). The short UPPS-P is a measure of impulsivity that produces five subscales of urgency: positive urgency, negative urgency, lack of premeditation, lack of perseverance, and sensation seeking. Each subscale has four items 
ranging from 1 to 4 (some of which are reversed coded), and these items are averaged for a score ranging from 1 (low) to 4 (high) points (continuous). These subscales were divided into two categories: scores below 2.5 and scores of 2.5 or above. The P.1 item of the SIPS is a Likert scale assessing the severity of unusual thought content/delusional ideas from 0 (absent) to 6 (severe and psychotic). SIPS scores were operationalized into two categories, low (scores 1-3) or high (scores of 4-6).

At each follow-up assessment, the MacArthur Community Violence Interview (MCVI) was used to assess the rates and types of violent behavior that had occurred between follow-ups (Appelbaum et al., 2000; Steadman et al., 1998; Swanson et al., 2006). The MCVI is a semistructured questionnaire that assesses and characterizes occurrences of violent behavior, including severity and frequency of the behavior, the target of the behavior, and the location where the behavior occurred. The MCVI also assesses violence directed at the participant. In this study, we defined violence as any act reported by the participant and did not require injury to the target to be counted as violence. Follow-ups were scheduled for months 3, 6, 9 and 12. However, if a patient missed a follow-up and completed the next follow-up, they were asked about violent behavior occurring between study contacts. Collateral information about violence was gathered from clinicians and from Webcrims, an online public database of court dates in NY State that contains information about arrest records.

The primary outcome of interest was engagement in violence during follow-up (binary: yes/no). Individuals who reported engaging in violence on the MCVI at least once during the follow-up period were categorized as having engaged in violence; if an individual did not report violence (either during the study period, or prior to leaving treatment or being lost to follow-up), they were categorized as having not engaged in violence. A secondary outcome of interest included presence of victimization during follow-up (binary: yes/no; see supplemental materials). A similar method of categorization was used to identify individuals who were targets of violence (i.e., reported victimization on the MCVI).

\section{Statistical Analyses}

Descriptive summaries of baseline demographic, social and clinical characteristics were computed overall and by engagement in violence during follow-up. Differences between groups were assessed using Fisher's exact tests (FET) for categorical variables and t-tests for continuous variables. Fisher's exact tests were computed for all categorical measures due to all measures having at least $20 \%$ of cells with expected cell counts less than 5 .

Further, to assess the predictive performance of baseline risk assessment measures on violence outcome, sensitivity, specificity, positive predictive value, and negative predictive value were computed along with exact binomial 95\% confidence intervals (CI). The receiver operator characteristic (ROC) curves were computed along with the corresponding area under the curve (AUC) from logistic regression models predicting engagement in violence during follow-up. The AUC evaluates how well each baseline risk assessment distinguishes between the outcome classes, with AUCs significantly different than 0.5 indicating prediction better than chance. All metrics were computed separately for each baseline risk assessment. A final multivariable logistic regression model was fit using a backwards selection process to find the most parsimonious set of predictors associated with significant improvements in AUC beyond individual assessments alone. All statistical tests were two-sided with an alpha level of 5\%, and were performed using SAS version 9.4 (SAS Institute, Cary NC). Due to the exploratory nature of these aims, results were not corrected for multiple comparisons.

This study was performed in line with the principles of the Declaration of Helsinki. Approval was granted by the New York State Psychiatric Institute's Institutional Review Board (IRB) (April 2019; Number 7787). The authors have no known conflicts of interest to report. All authors certify their responsibility for this manuscript.

\section{Results}

\section{Sample and Feasibility}

Descriptive summaries of the sample are presented in Table 1. Individuals were on average 24.1 years old $(\mathrm{SD}=3.3$ years $)$ and predominantly male $(\mathrm{n}=24,80 \%)$. The sample was mostly White $(\mathrm{n}=18,60 \%)$, with approximately a third identifying as Hispanic or Latino $(n=9,30 \%)$. Half had current tobacco use $(\mathrm{n}=15,50 \%)$, about a quarter endorsed current alcohol use $(\mathrm{n}=8,26.7 \%)$ and approximately two-fifths had current marijuana use $(n=13,43.3 \%)$. No one who expressed interest and was referred to the study declined participation during the consent process.

All recruited individuals completed all the baseline assessments, without any missing data. Initial follow-up rates were high; there were 28 currently in care at month 3 and 25 completed assessments (89.3\%). However, following transition to virtual follow-up because of the COVID19 pandemic, completion rates decreased to between 60 and $70 \%$ at each follow-up timepoint. There were 26 individuals in care at month 6 (19 completed assessments; $73.1 \%), 22$ at month 9 (13 completed assessments; 59.1\%), and 21 at month 12 (13 completed assessments; $61.3 \%$ ). This reflected multiple challenges of conducting research during a global pandemic, including that participants were 
Table 1 Descriptive summaries of baseline characteristics overall and by engagement in violence

\begin{tabular}{|c|c|c|c|c|}
\hline & $\begin{array}{l}\text { Sample } \\
\mathrm{N}=30\end{array}$ & $\begin{array}{l}\text { Engaged in violence } \\
\mathrm{N}=6\end{array}$ & $\begin{array}{l}\text { Did not } \\
\text { engage in } \\
\text { violence } \\
\mathrm{N}=24\end{array}$ & Test statistics \\
\hline Age [mean in years] (SD) & $24.1(3.3)$ & $22.4(3.3)$ & $24.6(3.1)$ & $\begin{array}{l}t(28)=-1.47^{a} \\
p=0.153\end{array}$ \\
\hline Gender [n (\% Male)] & $24(80.0)$ & $2(33.3)$ & $22(91.7)$ & $\begin{array}{l}\text { FET }^{\mathbf{b}} \\
\mathbf{p}=\mathbf{0 . 0 0 7}\end{array}$ \\
\hline \multicolumn{5}{|l|}{ Race $[\mathrm{n}(\%)]$} \\
\hline Asian & $2(6.7)$ & $1(16.7)$ & $1(4.2)$ & \multirow{4}{*}{$\begin{array}{l}\text { FET }^{b} \\
p=0.58\end{array}$} \\
\hline Black/African American & $8(26.7)$ & $2(33.3)$ & $6(25.0)$ & \\
\hline White & $18(60.0)$ & $3(50.0)$ & $15(62.5)$ & \\
\hline $\begin{array}{l}\text { Middle Eastern/North African } \\
\text { (MENA) }\end{array}$ & $2(6.7)$ & $0(0.0)$ & $2(8.3)$ & \\
\hline Ethnicity [n (\% Hispanic or Latino)] & $9(30.0)$ & $1(16.7)$ & $8(33.3)$ & $\begin{array}{l}\text { FET }^{b} \\
p=0.637\end{array}$ \\
\hline \multicolumn{5}{|l|}{ Diagnosis [n (\%)] } \\
\hline Schizophrenia $^{c}$ & $22(73.3)$ & $4(66.7)$ & $18(75.0)$ & $\begin{array}{l}\mathrm{FET}^{\mathrm{b}} \\
\mathrm{p}=0.645\end{array}$ \\
\hline Schizoaffective disorder & $6(20.0)$ & $1(16.7)$ & $5(20.8)$ & $\begin{array}{l}\mathrm{FET}^{\mathrm{b}} \\
\mathrm{p}=1.00\end{array}$ \\
\hline Bipolar disorder & $2(6.7)$ & $1(16.7)$ & $1(4.2)$ & $\begin{array}{l}\mathrm{FET}^{\mathrm{b}} \\
\mathrm{p}=0.366\end{array}$ \\
\hline Obsessive compulsive disorder & $3(10.0)$ & $2(33.3)$ & $1(4.2)$ & $\begin{array}{l}\text { FET }^{\mathrm{b}} \\
\mathrm{p}=0.094\end{array}$ \\
\hline \multicolumn{5}{|l|}{ Current substance use [n (\%)] } \\
\hline Tobacco $^{\mathrm{d}}$ & $15(50.0)$ & $3(50.0)$ & $12(50.0)$ & $\begin{array}{l}\text { FET }^{\mathrm{b}} \\
\mathrm{p}=1.0\end{array}$ \\
\hline Alcohol & $8(26.7)$ & $2(33.3)$ & $6(25.0)$ & $\begin{array}{l}\mathrm{FET}^{\mathrm{b}} \\
\mathrm{p}=0.645\end{array}$ \\
\hline Marijuana & $13(43.3)$ & $2(33.3)$ & $11(45.8)$ & $\begin{array}{l}\text { FET }^{b} \\
p=0.673\end{array}$ \\
\hline Any other drug use & $1(3.3)$ & $1(16.7)$ & $0(0.0)$ & $\begin{array}{l}\text { FET }^{b} \\
p=0.20\end{array}$ \\
\hline
\end{tabular}

Bold is $\mathrm{p}<0.05$

${ }^{\mathrm{a}} \mathrm{t}$-tests for continuous variables

${ }^{\text {b}}$ Fisher's exact tests were run for categorical measures due to at least $20 \%$ of cells having expected cell counts less than 5

${ }^{\mathrm{c}}$ This category includes diagnoses of schizophrenia and unspecified schizophrenia spectrum and other psychotic disorder

${ }^{\mathrm{d}}$ Includes vaping tobacco products no longer attending in-person appointments, which limited the clinic's ability to deliver reminders from study staff. Additionally, many participants experienced financial challenges from the pandemic, which resulted in housing instability (i.e., frequent address changes), disconnected phone numbers, and intermittent internet access. Despite this, 25 participants completed at least one follow-up assessment (83.3\%). Additional collateral information was obtained from clinicians as well as review of Webcrims and did not reveal any additional episodes of violence or victimization that were not previously reported on the MCVI.

\section{Engagement in Violence}

Of the 30 individuals with baseline risk assessments, 6 $(20 \%)$ reported engaging in violence at least once during the study period. Specifically, there were three episodes of throwing something; two of slapping someone; and two of pushing, grabbing, or shoving someone (one person threw something and slapped someone during the same incident). 
These episodes were commonly preceded by participants not taking antipsychotic medications $(n=5)$ and by feelings of anger $(n=2)$. Two participants reported taking time off from work or school following the episode of violence, and one individual was taken to the hospital for psychiatric evaluation. Overall, those who reported engaging in violence during the study period were more likely to be female $(66.7 \%$ female versus $8.3 \%$ female; FET, $\mathrm{p}=0.007$ ) (see Table 1 ). Other demographic and clinical characteristics did not significantly differ between those who did and did not engage in violence.

\section{Risk Assessment}

Most individuals were assessed as low risk with the HCR$20(n=20,66.7 \%$ low risk $)$ and the COVR $(n=26,86.7 \%$ very low or low risk), and assessed themselves as being at low risk of future violence on the self-assessment $(n=26$, $86.7 \%$ no risk) (see Table 2). Additionally, most individuals had no history of violence $(n=21,70.0 \%)$ according to item H1 on the HCR-20. Scores on these tools and the SIPS P1 item did not differ between those who did and did not engage in violence during the follow-up period (see Table 2). Of the UPPS-P subscales of impulsivity, the group that engaged in violence had higher levels of negative urgency $(\mathrm{t}(28)=2.21, \mathrm{p}=0.035)$ and lower levels of
Table 2 Descriptive summaries of baseline assessments overall and by engagement in violence

\begin{tabular}{|c|c|c|c|c|}
\hline & $\begin{array}{l}\text { Sample } \\
\mathrm{N}=30\end{array}$ & $\begin{array}{l}\text { Engaged in violence } \\
\mathrm{N}=6\end{array}$ & $\begin{array}{l}\text { Did not } \\
\text { engage in } \\
\text { violence } \\
\mathrm{N}=24\end{array}$ & Test statistics \\
\hline \multicolumn{5}{|c|}{$\mathrm{HCR}^{2} 20$ case prioritization $^{\mathrm{c}}[\mathrm{n}(\%)]$} \\
\hline Low risk & $20(66.7)$ & $5(83.3)$ & $15(62.5)$ & \multirow{2}{*}{$\begin{array}{l}\text { FET, } \\
p=0.633^{b}\end{array}$} \\
\hline Elevated risk & $10(33.3)$ & $1(16.7)$ & $9(37.5)$ & \\
\hline \multicolumn{5}{|l|}{ History of violence ${ }^{\mathrm{d}}[\mathrm{n}(\%)]$} \\
\hline No & $21(70.0)$ & $4(66.7)$ & $17(70.8)$ & \multirow{2}{*}{$\begin{array}{l}\text { FET, } \\
\mathrm{p}=1.0^{\mathrm{b}}\end{array}$} \\
\hline Yes & $9(30.0)$ & $2(33.3)$ & $7(29.2)$ & \\
\hline \multicolumn{5}{|l|}{$\operatorname{COVR}^{\mathrm{e}}[\mathrm{n}(\%)]$} \\
\hline Low risk & 26 (86.7) & $5(83.3)$ & $21(87.5)$ & \multirow{2}{*}{$\begin{array}{l}\text { FET } \\
\mathrm{p}=1.0^{\mathrm{b}}\end{array}$} \\
\hline Elevated risk & $4(13.3)$ & $1(16.7)$ & $3(12.5)$ & \\
\hline \multicolumn{5}{|l|}{ Self-assessment ${ }^{\mathrm{f}}[\mathrm{n}(\%)]$} \\
\hline No risk & 26 (86.7) & $5(83.3)$ & $21(87.5)$ & \multirow{2}{*}{$\begin{array}{l}\text { FET, } \\
\mathrm{p}=1.0^{\mathrm{b}}\end{array}$} \\
\hline Any risk & $4(13.3)$ & $1(16.7)$ & $3(12.5)$ & \\
\hline \multicolumn{5}{|l|}{ UPPS-P [average] (SD) } \\
\hline Negative urgency & $2.13(0.82)$ & $2.75(0.88)$ & $1.97(0.75)$ & $\begin{array}{l}t(28)=2.21 \\
p=0.035^{a}\end{array}$ \\
\hline Positive urgency & $1.86(0.67)$ & $1.92(0.79)$ & $1.84(0.65)$ & $\begin{array}{l}\mathrm{t}(28)=0.236 \\
\mathrm{p}=0.815^{\mathrm{a}}\end{array}$ \\
\hline Lack of perseverance & $1.89(0.56)$ & $1.83(0.70)$ & $1.91(0.54)$ & $\begin{array}{l}t(28)=-0.281 \\
p=0.781^{a}\end{array}$ \\
\hline Lack of premeditation & $1.56(0.48)$ & $1.67(0.52)$ & $1.53(0.48)$ & $\begin{array}{l}t(28)=0.610 \\
p=0.547^{a}\end{array}$ \\
\hline Sensation seeking & $2.45(0.71)$ & $1.92(0.51)$ & $2.58(0.67)$ & $\begin{array}{l}t(28)=-2.205 \\
p=0.036^{a}\end{array}$ \\
\hline SIPS P1 item [average] SD & $3.53(1.70)$ & $3.17(1.33)$ & $3.63(1.79)$ & $\begin{array}{l}t(28)=-0.59 \\
p=0.563^{a}\end{array}$ \\
\hline
\end{tabular}

Bold is $\mathrm{p}<0.05$

${ }^{a}$ t-tests for continuous variables

${ }^{b}$ Fisher's exact tests were run for categorical measures due to at least $20 \%$ of cells having expected cell counts less than 5

${ }^{c}$ Low risk is a rating of low; elevated risk is a rating of moderate or high

${ }^{\mathrm{d}}$ Based on the HCR-20 item H1, history of violence

${ }^{\mathrm{e}}$ Low risk is a rating of very low or low on the COVR; elevated risk is a rating of average, high or very high risk

${ }^{\mathrm{f}}$ Low risk is a self-assessment of 0 ; any risk is a score of 1 and above 
Table 3 Predictive utility of baseline risk assessments on classifying engagement in violence

\begin{tabular}{|c|c|c|c|c|c|}
\hline & Sensitivity \% $(95 \% \mathrm{CI})^{\mathrm{g}}$ & Specificity $\%(95 \% \text { CI })^{\mathrm{g}}$ & $\begin{array}{l}\text { Positive predictive } \\
\text { value } \%(95 \% \mathrm{CI})^{\mathrm{g}}\end{array}$ & $\begin{array}{l}\text { Negative predictive } \\
\text { value } \%(95 \% \mathrm{CI})^{\mathrm{g}}\end{array}$ & $\operatorname{AUC}(95 \% \mathrm{CI})^{\mathrm{g}}$ \\
\hline HCR-20 $0^{\mathrm{a}}$ & $16.7(0.42-64.1)$ & $62.5(40.6-81.2)$ & $10(0.25-44.5)$ & 75 (50.9-91.3) & $0.604(0.413-0.795)$ \\
\hline History of violence ${ }^{b}$ & $33.3(4.3-77.7)$ & $70.8(48.9-87.4)$ & $22.2(2.8-60.0)$ & $81.0(58.1-94.6)$ & $0.521(0.294-747)$ \\
\hline $\operatorname{COVR}^{\mathrm{c}}$ & $16.7(0.42-64.1)$ & $87.5(67.6-97.3)$ & $25(0.63-80.6)$ & 80.8 (60.7-93.4) & $0.521(0.344-0.698)$ \\
\hline Self-assessment ${ }^{\mathrm{d}}$ & $16.7(0.42-64.1)$ & $87.5(67.6-97.3)$ & $25(0.63-80.6)$ & 80.8 (60.7-93.4) & $0.521(0.344-0.698)$ \\
\hline SIPS $^{\mathrm{e}}$ & $66.7(22.3-95.7)$ & $50(29.1-70.9)$ & $25(7.3-52.4)$ & $85.7(57.2-98.2)$ & $0.583(0.353-0.814)$ \\
\hline Negative urgency ${ }^{\mathrm{f}}$ & $83.3(35.9-99.6)$ & $62.5(40.6-81.2)$ & $35.7(12.8-64.9)$ & $93.8(69.8-99.8)$ & $0.729(0.538-0.92)$ \\
\hline Sensation seeking ${ }^{\mathrm{f}}$ & $33.3(4.3-77.7)$ & $33.3(15.6-55.3)$ & $11.1(1.4-34.7)$ & $66.7(34.9-90.1)$ & $0.667(0.439-0.895)$ \\
\hline
\end{tabular}

${ }^{\mathrm{a}}$ Abnormal test: rating of moderate or high

${ }^{b}$ Abnormal test: rating of 2 or 3 on the HCR-20 item H1

${ }^{\mathrm{c}}$ Abnormal test: rating above low (i.e., average, high, or very high risk)

${ }^{\mathrm{d}}$ Abnormal test: any score $>0$

${ }^{\mathrm{e}}$ Abnormal test: any score $\geq 4$

${ }^{f}$ Abnormal test: any score $\geq 2.5$

${ }^{\mathrm{g}}$ presented with exact confidence intervals

sensation seeking $(\mathrm{t}(28)=-2.205, \mathrm{p}=0.036)$. The other impulsivity subscales did not significantly differ between groups.

\section{Predictive Utility of Risk Assessments on Violence}

The sensitivity, specificity, positive and negative predictive values, and AUCs are presented in Table 3. In general, the sensitivities of the baseline risk assessments were low to moderate (ranging from 16.7 to $66.7 \%$ ), except for Negative urgency having the highest sensitivity of $83.3 \%$. Specificities were low to moderate (ranging from 33.3 to $87.5 \%$ ). Additionally, the positive predictive values were low (ranging from 10 to $35.7 \%$ ) due to the low prevalence of violence in this sample, and the negative predictive values were moderate to high (ranging from 66.7 to $93.8 \%$ ). AUCs were mostly low (ranging from 0.521 to 0.667 ), with only negative urgency reaching statistical significance (AUC $=0.729,95 \%$ $\mathrm{CI}=[0.538,0.920])$. Further, in multivariable models, the most parsimonious set of predictors leading to a significant increase in AUC beyond that of negative urgency alone $\left(\chi^{2}\right.$ $(1)=10.4, p=0.0013)$ included negative urgency, COVR and sensation seeking (AUC $=0.879,95 \% \mathrm{CI}=[0.669$, 1.000]).

\section{Victimization}

Six episodes of victimization were reported by five participants (see Table 4). Two of these participants had also engaged in violence, though the relationship between being a target of violence and engaging in violence was not statistically significant $\left(\chi^{2}(1)=1.50, p=0.254\right)$. There were no significant differences in demographics or risk assessments for participants who were targets of violence and those who were not (see Supplemental Tables 1 and 2).

\section{Discussion}

This study sought to establish the feasibility, acceptability, and clinical utility of different approaches for assessing violence risk for EIS clients. This 12-month longitudinal pilot, spanning November 2019 to February 2021, overlapped with a global pandemic that dramatically changed the nature of this research. In the process, it exposed challenges of conducting research with a vulnerable group susceptible to many of the socioeconomic impacts of the COVID-19 pandemic, including reduced access to health care and housing instability. Despite these challenges, this study demonstrated the feasibility and acceptability of research related

Table 4 Episodes in which participants were targets of violence

\begin{tabular}{llll}
\hline Month 3 & Month 6 & Month 9 & Month 12 \\
\hline - Pushed, grabbed or shoved; something was thrown at them; and & - Slapped & - No reported episodes & - No reported episodes \\
they were kicked, bitten or choked & - Attempted sexual assault & \\
- Pushed, grabbed or shoved & - Pushed, grabbed or shoved & \\
- Threatened with a knife or a gun & & \\
\hline
\end{tabular}


to violence at EIS clinics, including the use of structured violence risk assessment. This is important as structured violence risk assessments can help EIS clinics improve the accuracy and transparency of violence risk assessments, compared to unaided clinical judgment which can embed racial bias - either explicitly or implicitly - in ways that are difficult to identify or challenge (Monahan, 2017; Neufeld, 2018; Skeem \& Lowenkamp, 2016, 2020). In comparison to most other studies on violence related to schizophrenia, this study is unusual in that the data were collected prospectively, exclusively for the purpose of studying violence, utilizing multiple methods of measuring violence (i.e., self-report and arrest records), and focusing specifically on young adults with early psychosis receiving treatment in an EIS setting (Appelbaum, 2019).

This study has limitations. The first limitation is its small sample. Second, all participants were young adults with early psychosis receiving treatment in EIS settings, which may differ from other young adults with early psychosis who may seek treatment in non-specialty mental health clinics or may not seek treatment. The study utilized a single rater for the risk assessment tools, which could introduce systemic bias in the process. To mitigate this limitation, the rater was a forensically trained psychiatrist, with formal training in risk assessment tools with clinical experience working with this population. In addition, conducting longitudinal research during the COVID-19 pandemic introduced unusual factors such as clinics being closed, schools transitioning to remote learning, workplaces furloughing or laying off many employees, and increased time spent at home (rather than in public or other social areas). Any of these factors could have affected the incidence of violent behavior. In addition, whether the participants developed COVID-19 was not tracked, as COVID-19 was not widely recognized until after the study was underway. While it is possible that more severe cases of COVID-19 may have limited study participants' ability to engage in violence due to either medical instability or isolation, this study consisted of younger individuals (who are less likely to develop severe illness) and the longitudinal study design captures 12 months of behavior (while acute COVID-19 symptoms typically last 14-21 days) (Cohen \& Blau, 2021; Nguyen et al., 2021). There is also concern that structured risk assessment tools can replicate existing racial discrimination, though new research is emerging to has suggested strategies to help balance racial bias that may be incorporated into structured risk assessment (Skeem \& Lowenkamp, 2020; Starr, 2014).

Overall, this study found that most individuals with early psychosis in this study (who are in treatment at EIS clinics) were not at risk of violence. This was according to both structured risk assessment tools as well as longitudinal assessments of violent behavior. This finding is consistent with prior research that has found most people with serious mental illnesses, including early psychosis, are not at risk of violence (Large \& Nielssen, 2011; Nielssen et al., 2012; Rolin et al., 2018; Winsper et al., 2013). However, $20 \%$ of this sample did engage in at least one act of violent behavior over the 12-month follow-up. In most incidents of violent behavior, participants reported not taking antipsychotic medications in the preceding period. Interestingly, given the low sensitivity, none of the structured assessments (i.e., HCR-20, COVR, and self-assessment) appeared able to identify individuals at risk of violence (based on future behavior). This finding is consistent with prior research that has found that these tools have worse performance when used for people with schizophrenia, compared to other diagnoses such as personality disorders. This suggests that violence risk assessment tools may perform worse when used specifically for individuals with schizophrenia (including early psychosis) and that the clinical utility of these tools differs when they are implemented in settings that specifically treat people with schizophrenia, such as EIS clinics. This may be because these tools were developed for people with serious mental illnesses in general not specifically in people with early psychosis or schizophrenia (Grann et al., 2000; Singh et al., 2011). This finding may suggest that new tools for violence risk assessment may need to be developed for the EIS setting, rather than utilizing tools developed in other populations.

Violence itself was a rare event, with six participants ( $20 \%$ of the sample) engaging in at least one act of violent behavior over 12 months. Collateral information from both clinicians and publicly available criminal justice records did not reveal additional episodes of violence, suggesting the value of patient self-report. As in the MacArthur Violence Risk Assessment Study, violence was most commonly minor, i.e., throwing something, pushing/grabbing/shoving someone, or slapping someone (Steadman et al., 1998). In this sample, violence was more common among women. Many studies have shown that male sex is a risk factor for violence in the general population, but often not among people with serious mental illnesses (Brucato et al., 2019; Rolin et al., 2018, 2021; Steadman et al., 1998) and some studies have shown higher rates of violence among women with mental illnesses (Fazel et al., 2021).

Findings from this study suggest that violent behavior among young adults with early psychosis is associated with increased negative urgency and decreased sensation seeking. While more research is needed to clarify the relationship between sensation seeking and violence, as studies of individuals without psychosis have suggested an association between higher levels of sensation seeking and violence, this study does suggest an important link between negative urgency (a component of impulsivity that describes the tendency to act impulsively when experiencing distress) and violence among people with psychosis that has been 
theorized in other studies (Adams \& Yanos, 2020; M. J. Hoptman et al., 2014). Impulsivity has been associated with violence during early psychosis in a recent post-hoc analysis of clinically collected data, which found that higher levels of impulsivity (assessed by 2 PANSS items, poor impulse control and difficulty in delaying gratification) was associated with violent behavior over a 36-month follow-up (Moulin, Baumann, et al., 2018; Moulin, Golay, et al., 2018). However, this analysis consisted of data collected for other purposes and did not examine impulsivity in a detailed way. More recently, a relationship between negative urgency and violence was suggested in a recent 2020 review of violence among individuals with psychosis (Adams \& Yanos, 2020). This relationship among violence, psychosis, and negative urgency was supported by a study examining impulsivity and violence for adults with schizophrenia (Hoptman, 2015; Hoptman \& Ahmed, 2016; M. J. Hoptman et al., 2014). Among 33 patients with schizophrenia and schizoaffective disorder and 31 healthy controls, patients with mental illnesses had higher levels of urgency (positive and negative) and more aggression than healthy controls (M. J. Hoptman et al., 2014). Additionally, higher urgency scores were correlated with reductions in cortical thickness in brain areas including ventral prefrontal regions. However, measures of aggression were based on a cross-sectional self-report questionnaire about aggressive attitudes. In contrast, this study bolsters the proposed relationship between impulsivity and violence by: (1) prospective collection of data specifically about violence; (2) detailed examination of constructs of impulsivity; and (3) measurement of actual, reported violent behaviors (rather than attitudes). This finding, supported by an established neural circuit, identifies negative urgency as a potentially modifiable target for behavioral interventions to reduce violence, a much needed area of research (Faay \& Sommer, 2021).

This study demonstrates the feasibility of research specifically focused on violence among young adults with early psychosis. The findings also suggest potentially useful insights into violent behavior in a high-risk population (young adults with early psychosis) and introduce areas for further research, including interventions such as cognitivebehavioral therapies to modify impulsivity.

Supplementary Information The online version contains supplementary material available at https://doi.org/10.1007/s10597-021-00922-6.

Author Contributions SR, IN, IB, MW, TSS, LD, and PA helped design the study. SR collected the data with supervision and assistance from IN, IB, LD, and PA. SR did the preliminary data analyses, JS and RD completed the statistical analyses, MW supervised all data analyses. SR, JS, and RD drafted the manuscript. IN, IB, TSS, LD, and PA revised the manuscript. All authors agreed on the final version of the paper.
Funding Research reported in this publication was supported by the National Institute of Mental Health under award numbers P50MH115843, 5R01MH120597, L30MH120711, and $\mathrm{K} 23 \mathrm{MH} 126312$. The content is solely the responsibility of the authors and does not necessarily represent the official views of the National Institutes of Health.

\section{Declarations}

Conflict of interest The authors have no conflicts of interest to declare that are relevant to the content of this article.

\section{References}

Adams, S. W., \& Yanos, P. T. (2020). Pathways to aggression and violence in psychosis without longstanding antisocial behavior: A review and proposed psychosocial model for integrative clinical interventions. Psychiatry Research, 293, 113427. https://doi.org/ 10.1016/j.psychres.2020.113427

Appelbaum, P. S. (2019). In search of a new paradigm for research on violence and schizophrenia. American Journal of Psychiatry, 176(9), 677-679. https://doi.org/10.1176/appi.ajp.2019.19070678

Appelbaum, P. S., Robbins, P. C., \& Monahan, J. (2000). Violence and delusions: Data from the MacArthur violence risk assessment study. American Journal of Psychiatry, 157(4), 566-572. https:// doi.org/10.1176/appi.ajp.157.4.566

Arai, K., Takano, A., Nagata, T., \& Hirabayashi, N. (2016). Predictive accuracy of the historical-clinical-risk management-20 for violence in forensic psychiatric wards in Japan. Criminal Behaviour and Mental Health. https://doi.org/10.1002/cbm.2007

Azrin, S. T., Goldstein, A. B., \& Heinssen, R. K. (2016). Expansion of coordinated specialty care for first-episode psychosis in the US (Focal Point: Youth, Young Adults, and Mental Health, Issue.

Bello, I., Lee, R., Malinovsky, I., Watkins, L., Nossel, I., Smith, T., Ngo, H., Birnbaum, M., Marino, L., Sederer, L. I., Radigan, M., Gu, G., Essock, S., \& Dixon, L. B. (2017). OnTrackNY: The development of a coordinated specialty care program for individuals experiencing early psychosis. Psychiatric Services (washington, D. C.), 68(4), 318-320. https://doi.org/10.1176/appi.ps. 201600512

Brucato, G., Appelbaum, P. S., Lieberman, J. A., Wall, M. M., Feng, T., Masucci, M. D., Altschuler, R., \& Girgis, R. R. (2018). A longitudinal study of violent behavior in a psychosis-risk cohort. Neuropsychopharmacology, 43(2), 264-271. https://doi.org/10. 1038/npp.2017.151

Brucato, G., Appelbaum, P. S., Masucci, M. D., Rolin, S., Wall, M. M., Levin, M., Altschuler, R., First, M. B., Lieberman, J. A., \& Girgis, R. R. (2019). Prevalence and phenomenology of violent ideation and behavior among 200 young people at clinical high-risk for psychosis: An emerging model of violence and psychotic illness. Neuropsychopharmacology, 44(5), 907-914. https://doi.org/10. 1038/s41386-018-0304-5

Cartwright, J. K., Desmarais, S. L., Hazel, J., Griffith, T., \& Azizian, A. (2018). Predictive validity of HCR-20, START, and static-99R assessments in predicting institutional aggression among sexual offenders. Law and Human Behavior, 42(1), 13-25. https://doi. org/10.1037/lhb0000263

Chang, W. C., Chan, S. S., Hui, C. L., Chan, S. K., Lee, E. H., \& Chen, E. Y. (2015). Prevalence and risk factors for violent behavior in young people presenting with first-episode psychosis in Hong Kong: A 3-year follow-up study. Australian and New Zealand 
Journal of Psychiatry, 49(10), 914-922. https://doi.org/10.1177/ 0004867415603130

Cohen, P., \& Blau, J. (2021). COVID-19: Outpatient evaluation and management of acute illness in adults. In J. G. Elmore (Ed.), UpToDate. Retrieved November 8, 2021, from https://www. uptodate.com/contents/covid-19-outpatient-evaluation-and-manag ement-of-acute-illness-in-adults? search $=$ covid-19\& source $=$ search_result\&selectedTitle $=2 \sim 150 \&$ usage_type $=$ default $\&$ displ ay_rank $=2$

Coid, J. W., Ullrich, S., Kallis, C., Freestone, M., Gonzalez, R., Bui, L., Igoumenou, A., Constantinou, A., Fenton, N., Marsh, W., Yang, M., DeStavola, B., Hu, J., Shaw, J., Doyle, M., Archer-Power, L., Davoren, M., Osumili, B., McCrone, P., ... Bebbington, P. (2016). Programme grants for applied research. In improving risk management for violence in mental health services: A multimethods approach. NIHR Journals Library. https://doi.org/10.3310/pgfar 04160

Coupland, R. B. A., \& Olver, M. E. (2018). Assessing dynamic violence risk in a high-risk treated sample of violent offenders. Assessment. https://doi.org/10.1177/1073191118797440

Cyders, M. A., \& Smith, G. T. (2008). Emotion-based dispositions to rash action: Positive and negative urgency. Psychological Bulletin, 134(6), 807-828. https://doi.org/10.1037/a0013341

Cyders, M. A., Littlefield, A. K., Coffey, S., \& Karyadi, K. A. (2014). Examination of a short English version of the UPPS-P impulsive behavior scale. Addictive Behaviors, 39(9), 1372-1376. https:// doi.org/10.1016/j.addbeh.2014.02.013

Dixon, L. B., Goldman, H. H., Bennett, M. E., Wang, Y., McNamara, K. A., Mendon, S. J., Goldstein, A. B., Choi, C. W., Lee, R. J., Lieberman, J. A., \& Essock, S. M. (2015). Implementing coordinated specialty care for early psychosis: The RAISE connection program. Psychiatric Services (washington, D. C.), 66(7), 691-698. https://doi.org/10.1176/appi.ps.201400281

Douglas, K. S., Ogloff, J. R., Nicholls, T. L., \& Grant, I. (1999). Assessing risk for violence among psychiatric patients: The HCR-20 violence risk assessment scheme and the psychopathy checklist: Screening version. Journal of Consulting and Clinical Psychology, 67(6), 917-930.

Faay, M. D. M., \& Sommer, I. E. (2021). Risk and prevention of aggression in patients with psychotic disorders. American Journal of Psychiatry, 178(3), 218-220. https://doi.org/10.1176/appi. ajp.2020.21010035

Fazel, S., Singh, J. P., Doll, H., \& Grann, M. (2012). Use of risk assessment instruments to predict violence and antisocial behaviour in 73 samples involving 24827 people: Systematic review and metaanalysis. BMJ, 345, e4692. https://doi.org/10.1136/bmj.e4692

Fazel, S., Toynbee, M., Ryland, H., Vazquez-Montes, M., Al-Taiar, H., Wolf, A., Aziz, O., Khosla, V., Gulati, G., \& Fanshawe, T. (2021). Modifiable risk factors for inpatient violence in psychiatric hospital: Prospective study and prediction model. Psychological Medicine. https://doi.org/10.1017/s0033291721002063

Grann, M., Belfrage, H., \& Tengström, A. (2000). Actuarial assessment of risk for violence: Predictive validity of the VRAG and the historical part of the HCR-20. Criminal Justice and Behavior, 27(1), 97-114.

Harris, A. W., Large, M. M., Redoblado-Hodge, A., Nielssen, O., Anderson, J., \& Brennan, J. (2010). Clinical and cognitive associations with aggression in the first episode of psychosis. Australian and New Zealand Journal of Psychiatry, 44(1), 85-93. https:// doi.org/10.3109/00048670903270423

Heinssen, R. K., Goldstein, A. B., \& Azrin, S. T. (2014). Evidencebased treatments for first episode psychosis: Components of coordinated specialty care (RA1SE: Recovery After Initial Schizophrenia Episode, Issue.

Hoptman, M. J. (2015). Impulsivity and aggression in schizophrenia: A neural circuitry perspective with implications for treatment.
CNS Spectrums, 20(3), 280-286. https://doi.org/10.1017/s1092 852915000206

Hoptman, M. J., \& Ahmed, A. O. (2016). Neural foundations of moodinduced impulsivity and impulsive aggression in schizophrenia. Current Behavioral Neuroscience Reports, 3(3), 248-255. https:// doi.org/10.1007/s40473-016-0081-6

Hoptman, M. J., Antonius, D., Mauro, C. J., Parker, E. M., \& Javitt, D. C. (2014). Cortical thinning, functional connectivity, and moodrelated impulsivity in schizophrenia: Relationship to aggressive attitudes and behavior. American Journal of Psychiatry, 171(9), 939-948. https://doi.org/10.1176/appi.ajp.2014.13111553

Hutton, P., Parker, S., Bowe, S., \& Ford, S. (2012). Prevalence of violence risk factors in people at ultra-high risk of developing psychosis: A service audit. Early Intervention in Psychiatry, 6(1), 91-96. https://doi.org/10.1111/j.1751-7893.2011.00307.x

Large, M. M., \& Nielssen, O. (2011). Violence in first-episode psychosis: A systematic review and meta-analysis. Schizophrenia Research, 125(2-3), 209-220.

Lehman, A. F., Lieberman, J. A., Dixon, L. B., McGlashan, T. H., Miller, A. L., Perkins, D. O., Kreyenbuhl, J., McIntyre, J. S., Charles, S. C., \& Altshuler, K. (2004). Practice guideline for the treatment of partients with schizophrenia. American Journal of Psychiatry, 161(2 SUPPL.).

Maremmani, I., Lazzeri, A., Pacini, M., Lovrecic, M., Placidi, G. F., \& Perugi, G. (2004). Diagnostic and symptomatological features in chronic psychotic patients according to cannabis use status. Journal of Psychoactive Drugs, 36(2), 235-241. https://doi.org/ 10.1080/02791072.2004.10399734

McGlashan, T. H., Walsh, B. C., \& Woods, S. W. (2010). The psychosis-risk syndrome: Handbook for diagnosis and follow-up. Oxford University Press.

Monahan, J. (1984). The prediction of violent behavior: Toward a second generation of theory and policy. American Journal of Psychiatry, 141(1), 10-15. https://doi.org/10.1176/ajp.141.1.10

Monahan, J. (2017). Risk assessment in sentencing (Academy for Justice, a Report on Scholarship and Criminal Justice Reform, Issue). Retrieved January 27, 2021, from https://ssrn.com/abstr act $=3024016$

Monahan, J., Steadman, H. J., Appelbaum, P. S., Grisso, T., Mulvey, E. P., Roth, L. H., Robbins, P. C., Banks, S., \& Silver, E. (2006). The classification of violence risk. Behavioral Sciences and the Law, 24(6), 721-730. https://doi.org/10.1002/bsl.725

Moulin, V., Baumann, P., Gholamrezaee, M., Alameda, L., Palix, J., Gasser, J., \& Conus, P. (2018). Cannabis, a significant risk factor for violent behavior in the early phase psychosis. Two patterns of interaction of factors increase the risk of violent behavior: Cannabis use disorder and impulsivity; cannabis use disorder, lack of insight and treatment adherence. Frontiers in Psychiatry, 9, 294. https://doi.org/10.3389/fpsyt.2018.00294

Moulin, V., Golay, P., Palix, J., Baumann, P. S., Gholamrezaee, M. M., Azzola, A., Gasser, J., Do, K. Q., Alameda, L., \& Conus, P. (2018). Impulsivity in early psychosis: A complex link with violent behaviour and a target for intervention. European Psychiatry, 49, 30-36. https://doi.org/10.1016/j.eurpsy.2017.12.003

Neufeld, A. (2018). In defense of risk assessment tools. Retrieved January 27, 2021, from https://www.themarshallproject.org/2017/10/ 22/in-defense-of-risk-assessment-tools

Nguyen, J. L., Benigno, M., Malhotra, D., Reimbaeva, M., Sam, Z., Chambers, R., Hammond, J., \& Emir, B. (2021). Hospitalization and mortality trends among patients with confirmed COVID-19 in the United States, April through August 2020. Journal of Public Health Research. https://doi.org/10.4081/jphr.2021.2244

Nicholls, T. L., Ogloff, J. R., \& Douglas, K. S. (2004). Assessing risk for violence among male and female civil psychiatric patients: The HCR-20, PCL:SV, and VSC. Behavioral Sciences and the Law, 22(1), 127-158. https://doi.org/10.1002/bsl.579 
Nielssen, O. B., Malhi, G. S., McGorry, P. D., \& Large, M. M. (2012). Overview of violence to self and others during the first episode of psychosis. Journal of Clinical Psychiatry, 73(5), e580-e587.

Papapietro, D. J. (2019). Involving forensic patients in treatment planning increases cooperation and may reduce violence risk. Journla of the American Academy of Psychiatry and the Law, 47(1), 35-41. https://doi.org/10.29158/jaapl.003815-19

Pelizza, L., Leuci, E., Maestri, D., Quattrone, E., Azzali, S., Paulillo, G., Pellegrini, P., \& Raballo, A. (2021). Disorganization in first episode schizophrenia: Treatment response and psychopathological findings from the 2-year follow-up of the "Parma Early Psychosis" program. Journal of Psychiatric Research, 141, 293-300. https://doi.org/10.1016/j.jpsychires.2021.07.015

Peterson, J., Skeem, J., \& Manchak, S. (2011). If you want to know, consider asking: How likely is it that patients will hurt themselves in the future? Psychological Assessment, 23(3), 626-634. https:// doi.org/10.1037/a0022971

Purcell, R., Fraser, R., Greenwood-Smith, C., Baksheev, G. N., McCarthy, J., Reid, D., Lemphers, A., \& Sullivan, D. H. (2012). Managing risks of violence in a youth mental health service: A service model description. Early Intervention in Psychiatry, 6(4), 469475. https://doi.org/10.1111/j.1751-7893.2012.00372.x

Raucher-Chéné, D., Bodnar, M., Lavigne, K. M., Malla, A., Joober, R., \& Lepage, M. (2021). Dynamic interplay between insight and persistent negative symptoms in first episode of psychosis: A longitudinal study. Schizophrenia Bulletin. https://doi.org/10. 1093/schbul/sbab079

Ray, I., \& Simpson, A. I. F. (2019). Shared risk formulation in forensic psychiatry. Journal of American Academy of Psychiatry and the Law, 47(1), 22-28. https://doi.org/10.29158/jaapl.003813-19

Rolin, S. A., Bareis, N., Bradford, J.-M., Rotter, M., Rosenfeld, B., Pauselli, L., Compton, M. T., Stroup, T. S., Appelbaum, P. S., \& Dixon, L. B. (2021). Violence risk assessment for young adults receiving treatment for early psychosis. International Journal of Law and Psychiatry, 76, 101701. https://doi.org/10.1016/j.ijlp. 2021.101701

Rolin, S. A., Marino, L. A., Pope, L. G., Compton, M. T., Lee, R. J., Rosenfeld, B., Rotter, M., Nossel, I., \& Dixon, L. (2018). Recent violence and legal involvement among young adults with early psychosis enrolled in coordinated specialty care. Early Intervention in Psychiatry. https://doi.org/10.1111/eip.12675

Sada, A., Robles-Garcia, R., Martinez-Lopez, N., Hernandez-Ramirez, R., Tovilla-Zarate, C. A., Lopez-Munguia, F., Suarez-Alvarez, E., Ayala, X., \& Fresan, A. (2016). Assessing the reliability, predictive and construct validity of historical, clinical and risk management-20 (HCR-20) in Mexican psychiatric inpatients. Nordic Journal of Psychiatry, 70(6), 456-461. https://doi.org/10.3109/ 08039488.2016 .1159330
Singh, J. P., Grann, M., \& Fazel, S. (2011). A comparative study of violence risk assessment tools: A systematic review and metaregression analysis of 68 studies involving 25,980 participants. Clinical Psychology Review, 31(3), 499-513. https://doi.org/10. 1016/j.cpr.2010.11.009

Skeem, J., \& Lowenkamp, C. (2020). Using algorithms to address trade-offs inherent in predicting recidivism. Behavioral Sciences and the Law, 38(3), 259-278. https://doi.org/10.1002/bsl.2465

Skeem, J. L., \& Lowenkamp, C. T. (2016). Risk, race, and recidivism: Predictive bias and disparate impact. Criminology, 54(4), 680 712. https://doi.org/10.1111/1745-9125.12123

Skeem, J. L., Manchak, S. M., Lidz, C. W., \& Mulvey, E. P. (2013). The utility of patients' self-perceptions of violence risk: Consider asking the person who may know best. Psychiatric Services (washington, D. C.), 64(5), 410-415. https://doi.org/10.1176/appi. ps.001312012

Starr, S. B. (2014). Evidence-based sentencing and the scientific rationalization of discrimination [Article]. Stanford Law Review, 66(4), 803-872. < Go to ISI $>$ ://WOS:000336007200002

Steadman, H. J., Mulvey, E. P., Monahan, J., Robbins, P. C., Appelbaum, P. S., Grisso, T., Roth, L. H., \& Silver, E. (1998). Violence by people discharged from acute psychiatric inpatient facilities and by others in the same neighborhoods. Archives of General Psychiatry, 55(5), 393-401.

Swanson, J. W., Swartz, M. S., Van Dorn, R. A., Elbogen, E. B., Wagner, H. R., Rosenheck, R. A., Stroup, T. S., McEvoy, J. P., \& Lieberman, J. A. (2006). A national study of violent behavior in persons with schizophrenia. Archives of General Psychiatry, 63(5), 490-499. https://doi.org/10.1001/archpsyc.63.5.490

Webster, C. D., Douglas, K. S., Eaves, D., \& Hart, S. D. (1997). Assessing risk of violence to other. In Impulsivity: Theory, assessment and treatment (pp. 251-277). Guilford Press.

Whiteside, S. P., \& Lynam, D. R. (2001). The five factor model and impulsivity: Using a structural model of personality to understand impulsivity. Personality and Individual Differences, 30(4), 669-689. https://doi.org/10.1016/S0191-8869(00)00064-7

Winsper, C., Ganapathy, R., Marwaha, S., Large, M., Birchwood, M., $\&$ Singh, S. P. (2013). A systematic review and meta-regression analysis of aggression during the first episode of psychosis. Acta Psychiatrica Scandinavica, 128(6), 413-421.

Publisher's Note Springer Nature remains neutral with regard to jurisdictional claims in published maps and institutional affiliations. 